\title{
Thermochromatographic behavior of iodine in fused silica columns when evaporated from lead-bismuth eutectic
}

\author{
Erik Karlsson $^{1,2} \cdot$ Jörg Neuhausen $^{1}$ (D) $\cdot$ Robert Eichler $^{1,2} \cdot$ Alexander Aerts $^{3} \cdot$ Ivan I. Danilov $^{1,2} \cdot$ Alexander Vögele $^{1}$. \\ Andreas Türler ${ }^{2}$
}

Received: 23 June 2020 / Accepted: 22 September 2020 / Published online: 11 October 2020

(c) The Author(s) 2020

\begin{abstract}
As a step toward licensing a lead-bismuth eutectic (LBE) based reactor design, the adsorption behavior of iodine evaporated from LBE on fused silica was examined. Using inert and reducing carrier gases, depositions with an adsorption enthalpy of -95 to $-113 \mathrm{~kJ} \mathrm{~mol}^{-1}$ were observed. These depositions are compatible with a single species, tentatively identified as bismuth monoiodide, BiI. When introducing oxidizing conditions, multiple iodine species with higher volatility form, with adsorption enthalpies ranging from -67 to $-86 \mathrm{~kJ} \mathrm{~mol}^{-1}$. Based on an empirical correlation one of these species was identified as monatomic iodine. This work provides fundamental understanding of the LBE/iodine gaseous chemistry and related adsorption deposition behavior.
\end{abstract}

Keywords Iodine $\cdot$ Lead-bismuth eutectic $\cdot$ Thermochromatography $\cdot$ Fused silica $\cdot$ Adsorption

\section{Introduction}

To cope with the growing stockpiles of high-level nuclear waste around the world, new reactor designs are required. These new designs include features that broaden the use cases as well as increase the safety of the reactors. One example of such a design is a fast reactor, which is capable of reducing the total volume of the end of cycle (EOC) waste. Long-lived minor actinides present in the fuel are also burned off, reducing the required storage time by two orders of magnitude [1]. This kind of reactor can also vastly increase the energy production efficiency from fresh uranium fuel due to it being able to make better use of the ${ }^{238} \mathrm{U}$

Electronic supplementary material The online version of this article (https://doi.org/10.1007/s10967-020-07420-1) contains supplementary material, which is available to authorized users.

Jörg Neuhausen

joerg.neuhausen@psi.ch

1 Laboratory of Radiochemistry, Paul Scherrer Institut (PSI), Forschungsstrasse 111, 5232 Villigen, Switzerland

2 Department of Chemistry and Biochemistry, University of Bern, Freiestrasse 3, 3012 Bern, Switzerland

3 Chemistry and Conditioning Programme, Belgian Nuclear Research Centre, Boeretang 200, 2400 Mol, Belgium than a regular thermal reactor [2]. For these types of reactors water is not a viable option as a primary coolant as it would moderate the neutrons to thermal energies which are less suitable for fissioning ${ }^{238} \mathrm{U}$ as well as minor actinides [3]. Proposed coolants for these reactors are instead gases, molten salts or liquid metals such as lead, sodium or LBE (lead-bismuth eutectic) [4]. This work focuses on the LBEbased subset of heavy liquid metal cooled fast reactors.

These reactor designs have extended capabilities compared to light-water reactors but they also present new challenges concerning the chemistry involved. Whereas water reactor chemistry has been studied extensively during thousands of reactor operation years, the knowledge base for heavy liquid metal cooled reactors is much smaller. Nearly all of the experience in operating and developing these reactors has been obtained in Russia for military purposes as a part of their nuclear powered submarine program [5]. The available published research performed in the specific area of coolant and radionuclide interaction chemistry in an LBE system has mainly been focused on polonium [6, 7]. Polonium isotopes (mainly ${ }^{210} \mathrm{Po}$ ) are the radionuclides with the highest potential radiological impact present in an LBE system which merits studying the element closely. The post irradiation examination of the MEGAPIE liquid LBE spallation target gave some insight into the chemistry of radionuclides in a large scale LBE-based nuclear facility. 
For example, the distribution of nuclides between steel surfaces of components and the LBE itself were studied, and polonium production rates predicted using particle transport codes have been confirmed by radiochemical analysis [8-10]. While the MEGAPIE experiment provided valuable qualitative and semi-quantitative information regarding radionuclide transport and retention in an LBE system, further experiments are required to assess the fundamental thermodynamic properties governing retention of radionuclides in the coolant and by surface adsorption effects.

The purpose of this work is obtaining a better thermodynamical understanding about the basic evaporation, transport and deposition behavior of iodine evaporated from LBE. Iodine is an important nuclide as it has a high fission yield from uranium fission and is one of the main contributors to radioactive dose to the public from release in the event of a severe accident, mainly due to its volatility and ease of absorption into the human body in the thyroid gland [11]. In accident conditions in a light-water reactor, iodine is mainly emitted in gaseous form of which the majority quickly condenses. The remaining small fraction of iodine $(\sim 1-2 \%)$ is volatile and transported easily through the containment. In a light-water reactor, iodine is assumed to occur in large part as CsI. This is a favorable outcome from a safety perspective as CsI is soluble in water as well as not very volatile [12]. There is however still a risk of aerosol formation, facilitating transport.

In an LBE-cooled reactor with an abundance of lead and bismuth and a lack of water in contrast to an LWR-system, new chemical pathways for release of radionuclides such as iodine must be considered. In such a system the excess of the coolant components will promote the formation of bismuth and lead iodides. The first barriers toward release are the same as in a Gen III reactor, the fuel matrix and the fuel rod cladding. In the event of a fuel pin break, there is potential ingress of coolant into the fuel rod. This leads to a dissolution of fission products into the coolant, which are dispersed in the system. During normal operation the LBE surface would be exposed to an inert atmosphere, limiting the chance of further reactions occurring after the radionuclide has passed through the boundary layer between the coolant and the cover gas. Accidents which compromise the integrity of the systems in the reactor may introduce the presence of other gases such as oxygen from the atmosphere, steam from the secondary cooling system and hydrogen from the reaction of the steam with metal surfaces at high temperature. Though the probability for such an accident is very low, the behavior of iodine under these conditions still has to be studied to understand how to mitigate or avoid its consequences. In order to cover all these conditions, the experiments in this series will feature helium, hydrogen and oxygen as carrier gases in both controlled low moisture (dry) and water saturated (moist) conditions.
To study the evaporation, transport and deposition behavior of iodine released from LBE we utilize the knowledge and methodology from previous thermochromatography based adsorption studies on polonium in various gas atmospheres [13]. The method of thermochromatography used in this work is based on successive adsorption/desorption equilibria established between a chemical species and a surface in a temperature gradient and allows determining its affinity to this particular surface. To acquire a fundamental understanding of the behavior of iodine evaporated from LBE it is desirable to study its behavior in a well-known system. Therefore, the inert fused silica was chosen as an adsorbent. This choice is advantageous because empirical correlations exist which relate sublimation and adsorption enthalpies for certain chemical species on silica surfaces [14, 15]. These relations can be used to identify the molecular species of iodine occurring in the experiments. Additionally due to chemical similarities, the choice of fused silica as an adsorbent gives information regarding the iodine behavior on concrete, a major structural component in nuclear reactors [16].

\section{Experimental}

\section{Sample preparation}

The samples consisted of approximately $20-50 \mathrm{mg}$ of LBE (SIDECH, 99.999\%) mixed with 2\% of elemental tellurium (Sigma Aldrich, Batch: MKBW7373V, 99.999\%) prepared by heating the mixture inside a sealed evacuated fused silica ampoule to produce a homogeneous sample. Prior to mixing with tellurium, the oxygen content of the LBE was reduced by heating it in an evacuated tantalum-lined silica ampoule at $1000{ }^{\circ} \mathrm{C}$ for 6 to $8 \mathrm{~h}$. The reduced LBE was then mixed with 2 mass \% of tellurium and heated to $850{ }^{\circ} \mathrm{C}$ in another evacuated fused silica tube for $14 \mathrm{~h}$ with intermittent agitation. The obtained material was divided into batches of about $2 \mathrm{~g}$ each, which were subsequently irradiated for $3 \mathrm{~h}$ in the SINQ neutron source $\left(1 \times 10^{13} \mathrm{n} \mathrm{s}^{-1} \mathrm{~cm}^{-2}\right)$ to produce the nuclide of interest $\left({ }^{131} \mathrm{I}\right)$ by neutron activation of ${ }^{130} \mathrm{Te}$ to ${ }^{131} \mathrm{Te}$ followed by $\beta$-decay into ${ }^{131} \mathrm{I}$. The irradiated samples typically contained ca. $300 \mathrm{kBq}$ of ${ }^{131} \mathrm{I}$ per $\mathrm{g}$ of LBE directly after irradiation. Material from the same batch was used for a series of experiments within about 25 days after the irradiation, leading to a reduction of the iodine concentration of about a factor of 10 in the last used samples caused by decay. The amount of ${ }^{131}$ I activity in the individual 20 to $50 \mathrm{mg}$ samples used for the single experiments ranged from 1.5 to $15 \mathrm{kBq}$. The mole fractions of iodine in the LBE samples were calculated from the activities to range from ca. $x_{I}=10^{-10}$ for freshly irradiated samples down to ca. $x_{I}=10^{-11}$ for decayed samples. The irradiation also produces 
detectable levels of radioactive mercury, polonium as well as thallium and bismuth isotopes. These isotopes are however too short-lived, non-volatile/too volatile or not abundant enough to study using the techniques described in this work.

\section{Thermochromatography setup}

The experiments were conducted in two different gradient tube thermochromatography furnaces. These two furnaces were used for controlled low moisture (dry) and water saturated (moist) conditions, respectively. For the experiments in dry conditions a closed gas loop along with a starting furnace $\left(700{ }^{\circ} \mathrm{C}\right)$ to initially evaporate the sample was used, detailed in Fig. 1a. The gas loop featured a Sicapent ${ }^{\circledR}$ moisture absorber, a tantalum wool oxygen getter heated to $1000{ }^{\circ} \mathrm{C}$ and a dew point meter (Michell PuraOEM \& Michell Easidew EA2-TX-100 interchangeably) to monitor the moisture content. The furnace used for dry conditions was a homemade resistance heated furnace, while for the water saturated conditions a furnace manufactured by HTM Reetz $\mathrm{GmbH}$ was used. Both gradient furnaces featured an Inconel ${ }^{\circledR}$ shrouding tube into which the chromatographic column was inserted. For the water saturated experimental series, a once-through gas feed system was used and the experiment was initiated by pushing the sample into the hot zone using a pin mounted on a vacuum feedthrough to keep the mobile phase unchanged (see Fig. 1b). This setup also included a water bubbler to saturate the incoming gas with water at room temperature. The carrier gases used were helium, oxygen and hydrogen (all Messer ${ }^{\circledR}$ 5.0) to try to affect the chemical speciation in various ways depending on the oxidation or reduction potential of the gas. The flowrates for dry carrier gases were $25 \mathrm{ml} \mathrm{min}{ }^{-1}$ for $\mathrm{O}_{2}, 28 \mathrm{ml} \mathrm{min}^{-1}$ for $\mathrm{H}_{2}$ and $45 \mathrm{ml} \mathrm{min}^{-1}$ for $\mathrm{He}$. In water saturated conditions the flowrate was $25 \mathrm{ml} \mathrm{min}^{-1}$ for all gases. The gas flow was controlled using a mass flow controller (Brooks Instrument B.V., 5850S/E). The flow was verified using a mini-BUCK Calibrator M-5 from A.P. Buck Inc. Temperature gradients were applied from 700 to $1000{ }^{\circ} \mathrm{C}$ down to room temperature along the gas flow direction (Fig. 1). The gradients were measured by inserting a type- $K$ thermocouple in centimeter steps into the furnace. These gradients vary with the carrier gas and furnace used and are displayed for each condition in the figures presented in the results section. At the end of the gradient furnaces, charcoal filters were installed to catch species not deposited in the column to prevent spreading contaminations. For the experiments, each sample was placed in a $316 \mathrm{~L}$ stainless steel boat (approx. $3 \mathrm{~mm}$ wide and $15 \mathrm{~mm}$ long) which was inserted into a column made of fused silica ( $5 \mathrm{~mm}$ inner diameter, $1200 \mathrm{~mm}$ in length) with a piece of quartz wool positioned in front of it to catch aerosols potentially escaping the sample.

\section{Experimental methodology}

Before the experiments were started, a stable temperature gradient was established by running the furnace for $3 \mathrm{~h}$ with flowing carrier gas. In the dry experimental setup featuring the gas loop, the system was run until conditions such as gas moisture content were satisfactory $(<100$ volume $\mathrm{ppm})$ before starting the experiment. The experiment was started by either switching on the starting oven (Fig. 1a) or by shifting the initial sample into the hot zone of the gradient (Fig. 1b). Each experiment had then a duration of either 2 or $3 \mathrm{~h}$, initiated by the evaporation of the sample into the carrier gas. This evaporation process was continued for $1 \mathrm{~h}$ after the start of the experiment. After this, the evaporation was stopped by either retracting the sample from the evaporation zone (moist experiments) or by switching off the starting furnace (dry experiments). In water saturated conditions the experiment then continued for one additional hour, whereas in the dry experimental setup the experiment was sustained for two more hours after the starting furnace was turned off.

In the gas adsorption thermochromatography and Monte Carlo simulation section, a more detailed explanation of the events occurring during the experiment on a microscopic level is given. When the experiment is completed the column is measured in centimeter steps on an HPGe $\gamma$-detector (a)

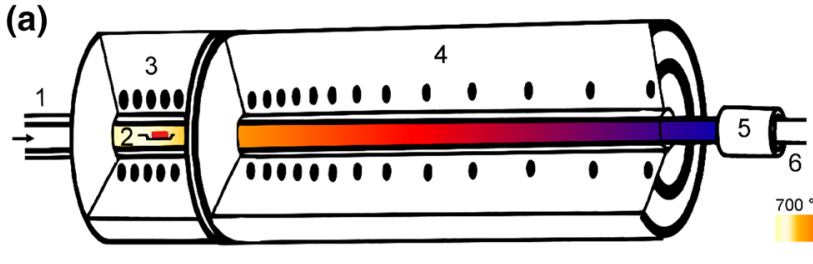

Fig. 1 Graphical representation of the applied thermochromatography setups. The color gradient illustrates the temperature gradient with the two applied starting temperatures $\left(700{ }^{\circ} \mathrm{C}, 1000{ }^{\circ} \mathrm{C}\right)$. The sample is evaporated on the left and carried with the gas flowing through the furnaces to the right. Left a: experimental setup for dry conditions: gas inlet (1), sample in sample boat (2), starter furnace (3), gradient

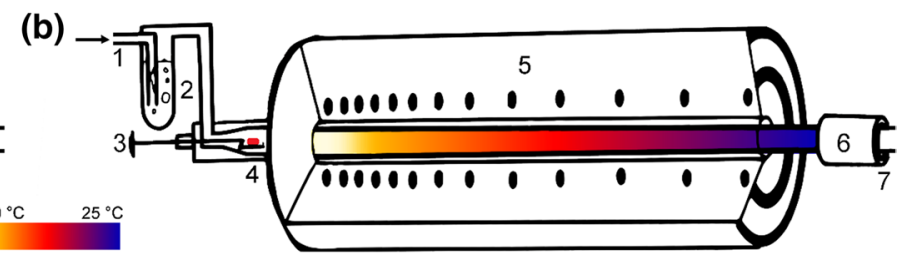

furnace (4), charcoal filter (5), gas outlet (6). Right b: experimental setup for water saturated conditions: gas inlet (1), bubbler for saturating gas with water (2), pusher pin to insert sample into hot zone (3), sample in sample boat (4), gradient furnace (5), charcoal filter (6), gas outlet (7). (Color figure online) 
collimated by a lead brick (thickness $14 \mathrm{~mm}$ ) with a $10 \mathrm{~mm}$ round opening for $300 \mathrm{~s}$ per centimeter. The data analysis of the activities was done using Canberra's Genie $2 \mathrm{k}^{\circledR}$ package. This yields a distribution of activity over the column, which is used as reference data for a Monte Carlo simulation of the experiment.

\section{Gas adsorption thermochromatography and Monte Carlo simulation}

After evaporation, the radionuclides are transported in the carrier gas along the declining temperature gradient. During this transport, the gaseous species containing the radionuclide undergoes numerous contacts with the surface of the column. Each time it comes into contact with the surface there are certain parameters influencing how long it will remain attached to the surface, e.g. in an adsorbed state. At some point in the wandering path of the radionuclide along the flow direction of the carrier gas, the radionuclide will eventually stick until the experimental time has expired.

The simulation used to assess the behavior of the system is based on the Monte Carlo (MC) methodology drawn up by Zvara in [17]. Every chemical species present in the system is imagined as a particle, each particle history is simulated separately as there is an assumption of no interaction between particles. After evaporation, the particle is transported along with the carrier gas flow. The MC model assumes a diffusion controlled movement of the particle in the carrier gas stream towards the surface. The required diffusion coefficient of the species in the carrier gas is approximated by the semi-empirical Gilliland equation [17]. Upon impact on the column surface, the particle adsorbs to it and sticks. The period of sticking is calculated via a Frenkellike ansatz connecting the adsorption time with the adsorption interaction potential, i.e. the adsorption enthalpy of the species on the surface over the most pronounced phonon vibration frequency of the surface material [17]. The single adsorption step is assumed to be reversible and repeats for an average number of surface encounters of gaseous molecules on a surface, which is estimated from the Boltzmann statistics. An average adsorption time is calculated multiplying the number of surface encounters with the period of each adsorption sticking. With a certain small chance, the particle is diffusing far enough away from the surface into the moving gas and is transported for another longjump. This is accounted as the real displacement within the column and thus within the temperature gradient. Then the particle diffuses again to the stationary surface while being transported. This looping calculation leads to a step-wise transport consisting of many adsorption-desorption events with intermediate rare real transport events in the carrier gas. Eventually, the particle decays or the experimental time is expired. The decay in-flight will lead to a non-observation in our experiment. As the nuclide in question has a halflife where $T_{1 / 2} \gg T_{\exp }$, this is seen as a negligible branch of the total events. If the particle is leaving the column during the experimental time, it will be measured in the charcoal trap. In that case, only an upper bound on the strength of the adsorption can be derived. If the particle sticks on the column surface and survives until the experimental time expires, it will be counted as measured. Experimental data such as carrier gas volume flow, column diameter, experimental time, and temperature gradient over the column is fed into the MC simulation. Using these parameters along with the measured deposition pattern, a guess for the adsorption enthalpy of the species $\left(\Delta H_{\text {ads }}\right)$ is entered as a measure for the strength of the interaction between the species and the column surface. This calculation is repeated typically for $10 \mathrm{~K}-10 \mathrm{M}$ particles. The resulting particle distribution is compared to the experimentally measured distribution. This guess of the only variable in the MCS-the adsorption enthalpy-is altered until the simulation result best fits what is observed in the experiment. The produced thermodynamic data can then be used to make assessments regarding the speciation and behavior of the radionuclide species evaporated and deposited in different conditions. In case of the simulations performed within this work, $50 \mathrm{k}$ particle histories were used for each simulation. This number of particle histories proved to be sufficient to simulate the activity distribution in the deposition peaks with sufficient statistics. The uncertainties for the adsorption enthalpies were determined by assuming a potential shift of the deposition peak by $\pm 1 \mathrm{~cm}$ and $\mathrm{a} \pm 5 \mathrm{ml} \mathrm{min}^{-1}$ carrier gas flow fluctuation.

\section{GEM calculations}

Gibbs energy minimization (GEM) calculations were performed using the GEM module of the HSC Chemistry ${ }^{\circledR}$ software package version 9.8.1.2 [18]. A system was set up containing solid phases, a liquid phase and a gas phase. The solid and gas phases comprised all solid and gas phase compounds of the elements studied $\left(\mathrm{Bi}, \mathrm{Pb}, \mathrm{Te}, \mathrm{I}, \mathrm{He}, \mathrm{H}_{2}, \mathrm{O}_{2}\right.$ ) incorporated in the database of HSC Chemistry ${ }^{\circledR}$. The solid compounds were treated as individual pure phases, while the gas phase was treated as an ideal mixture. The liquid phase comprised the elements $\mathrm{Bi}, \mathrm{Pb}, \mathrm{Te}$ and I. It was treated as an ideal dilute solution of iodine and tellurium in lead and bismuth at the eutectic composition, with thermodynamic activity coefficients derived from phase diagram information and data from evaporation experiments [manuscript in preparation]. Individual systems were set up for the different carrier gases. The initial compositions of these systems contained the carrier gas, $\mathrm{Bi}, \mathrm{Pb}, \mathrm{Te}$ and $\mathrm{I}$ in a molar ratio of 100:0.55:0.45:0.02:1 $\times 10^{-10}$, approximating the conditions of the experiments. For moist systems, an amount of $\mathrm{H}_{2} \mathrm{O}$ corresponding to the moisture levels measured in the 
experimental setup, i.e. $1 \%(10,000 \mathrm{ppm})$ of the cover gas (see Table 1) was added.

\section{Results and discussion}

The results from the experimental series on the adsorption of iodine evaporated from LBE on fused silica tubes are compiled below in Table 1. To give a more complete overview of the observed behavior, the measured chromatograms for each condition are also provided in Figs. 2 and 4. Iodine adsorbs on fused silica at relatively low temperatures with low absolute values of the adsorption enthalpies in dry helium and hydrogen. The main depositions occur from 100 to $180^{\circ} \mathrm{C}$, resulting in adsorption enthalpies of about $-105 \pm 10 \mathrm{~kJ} \mathrm{~mol}^{-1}$. In oxygen, more volatile species are observed with depositions seen at lower temperatures with part of the activity passing through room temperature conditions into the charcoal trap. Measurements regarding the evaporated fraction indicate a retention of iodine in the lead-bismuth in oxygen carrier gas, whereas almost complete evaporation of iodine from the LBE is observed when using helium and hydrogen regardless of the moisture content in the gas. This behavior could be explained based on several different phenomena. Either the oxides formed on the surface of the LBE induce retention through preventing the iodine from evaporating by occluding the surface or iodine compounds are formed which are non-volatile and are thus not evaporated. The evaporation in hydrogen and helium ranged from 97 to $99 \%$ whereas in oxygen it was $23-68 \%$, with no consistent differences observed for dry and moist conditions.

The mole fraction of tellurium in our samples is much higher than in the reactor case, however its use at rather high concentrations was necessary to produce samples containing enough ${ }^{131} \mathrm{I}$ as well as providing an easy way to introduce the iodine into the sample in a homogeneous way. Because the tellurium concentration in LBE is rather high and iodine is formed from tellurium distributed in the LBE matrix when irradiating the LBE samples, potential formation of tellurium iodides must be considered when interpreting the results. Indeed, depositions with adsorption enthalpies between -110 and $-120 \mathrm{~kJ} \mathrm{~mol}^{-1}$ observed in a recent thermochromatography study on neutron irradiated pure tellurium samples were attributed to tellurium iodides [19]. Thermodynamic data on tellurium iodides are scarce. Data are only available for one condensed phase compound at room temperature, $\mathrm{TeI}_{4}$ [20]. The Gibbs energy change for its reaction with $\mathrm{Pb}$ to form $\mathrm{PbTe}$ and $\mathrm{PbI}_{2}$ at room temperature is $-361 \mathrm{~kJ} \mathrm{~mol}^{-1}$. This instability with respect to decomposition into metal iodides and tellurides most likely also prevails for mixtures with low iodine content and at elevated temperatures. Thus, tellurium-iodine compounds, should they be present after irradiation, are expected to decompose upon melting the LBE, forming thermodynamically more stable

Table 1 Experimental conditions and corresponding results extracted from the measured chromatograms

\begin{tabular}{|c|c|c|c|c|c|c|c|}
\hline Exp & Carrier gas & $\begin{array}{l}\mathrm{H}_{2} \mathrm{O} \text { content of } \\
\text { gas }(\mathrm{ppm})^{\mathrm{b}}\end{array}$ & Dew point $\left({ }^{\circ} \mathrm{C}\right)$ & $-\Delta H_{\mathrm{ads}}\left(\mathrm{kJ} \mathrm{mol}^{-1}\right)$ & $T_{\mathrm{dep}}{ }^{131} \mathrm{I}\left({ }^{\circ} \mathrm{C}\right)$ & Presumed chemical species & $\begin{array}{l}\text { Evapo- } \\
\text { rated \% of } \\
{ }^{131} \mathrm{I}\end{array}$ \\
\hline I & Dry He & 5 & -65 & $100 \pm 10$ & 106 & BiI & No data \\
\hline II & & 50 & -48 & $96 \pm 10$ & 104 & BiI & $99 \%$ \\
\hline III & Dry $\mathrm{H}_{2}$ & 90 & -43 & $113 \pm 8$ & 181 & BiI & No data \\
\hline IV & & 65 & -45.7 & $\begin{array}{c}95 \pm 10 \\
149 \pm 8\end{array}$ & $\begin{array}{l}103 \\
330\end{array}$ & $\begin{array}{l}\mathrm{BiI} \\
(\mathrm{CsI})^{\mathrm{a}}\end{array}$ & $97 \%$ \\
\hline V & Dry $\mathrm{O}_{2}$ & 80 & -44 & $\begin{array}{l}86 \pm 4 \\
72 \pm 2\end{array}$ & $\begin{array}{l}68 \\
37\end{array}$ & $\begin{array}{l}\text { I } \\
\text { Iodine oxides and hydroxides }\end{array}$ & $58 \%$ \\
\hline VI & & 56 & -47 & $\begin{array}{l}81 \pm 3 \\
67 \pm 2\end{array}$ & $\begin{array}{l}68 \\
24\end{array}$ & $\begin{array}{l}\text { I } \\
\text { Iodine oxides and hydroxides }\end{array}$ & $68 \%$ \\
\hline VII & Moist He & $\sim 10,000$ & - & $108 \pm 7$ & 178 & BiI & $99 \%$ \\
\hline VIII & & $\sim 10,000$ & - & $114 \pm 8$ & 196 & BiI & $98 \%$ \\
\hline IX & Moist $\mathrm{H}_{2}$ & $\sim 10,000$ & - & $112 \pm 8$ & 183 & BiI & $99 \%$ \\
\hline $\mathrm{X}$ & & $\sim 10,000$ & - & $96 \pm 5$ & 112 & BiI & $99 \%$ \\
\hline XI & Moist $\mathrm{O}_{2}$ & $\sim 10,000$ & - & $80 \pm 3$ & 67 & I & $23 \%$ \\
\hline XII & & $\sim 10,000$ & - & $65 \pm 2$ & 25 & Iodine oxides and hydroxides & $64 \%$ \\
\hline
\end{tabular}

Listed are also the observed the deposition temperature $\left(T_{\text {dep }}\right)$ together with adsorption enthalpies $\left(-\Delta H_{\text {ads }}\right)$ extracted by Monte Carlo simulation, a hypothesis regarding the chemical speciation of that deposition and a value for the percentage of ${ }^{131}$ I evaporated from the sample

${ }^{a}$ Minor deposition from contamination, see text for explanation

${ }^{\mathrm{b}} \mathrm{H}_{2} \mathrm{O}$ content calculated using the measured dew point and the calculator at http://www.michell.com/uk/calculator/ 
(a)

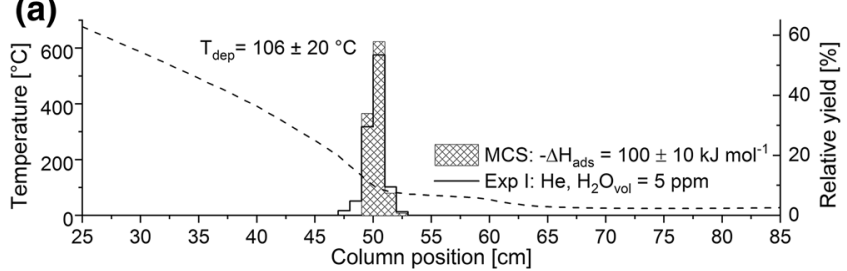

(c)

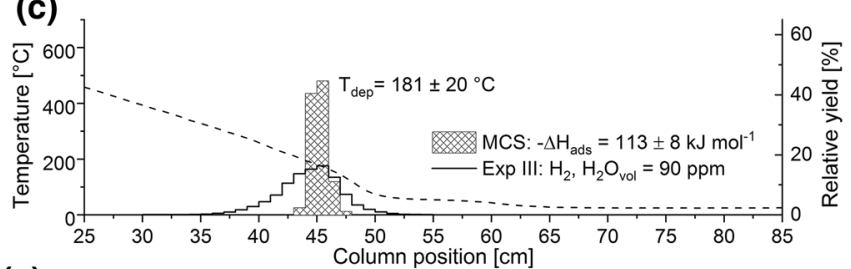

(e)

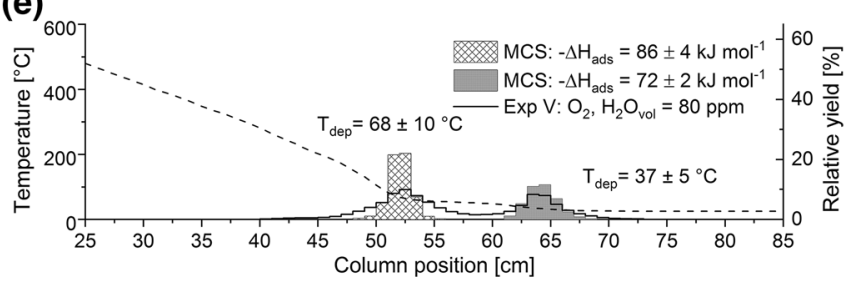

Fig. 2 Histograms of the iodine deposition patterns (black solid lines) observed in the experiments with fused silica columns in dry carrier gases. The dashed black line represents the temperature gradient over

complexes where iodine and tellurium are bound to lead or bismuth.

The shape and width of the peaks in the different experiments and their variation can be explained by a number of factors. Contributing factors are changes of the surface of the column, either via reactions with the cover gas, by thermally induced chemical changes or by coverage with macroscopic contaminants (e.g. Pb, Bi and/or their compounds). Another contributing factor is a change of the chemical state of the species during the transport, so-called transport reactions. From this reasoning the widest peaks should be expected for oxygen followed by hydrogen and helium. This is confirmed by our results presented in Figs. 2 and 4. Due to the extremely small mole fraction of iodine present in the samples used in these experiments $\left(\sim 10^{-10}\right.$ to $\left.10^{-11}\right)$, any options for the speciation of the molecular entity transported in the gas phase containing more than one iodine atom, such as $\mathrm{PbI}_{2}$ and $\mathrm{BiI}_{3}$ molecules, can be disregarded as the iodine concentration is too low to allow their formation. The interpretation of the observed chromatograms is based on the assumed formation of metal iodides with $\mathrm{Pb}$ and $\mathrm{Bi}$. These iodides are limited to $\mathrm{BiI}$ and $\mathrm{PbI}$ for the reasons explained before, the latter only existing in the gas phase. In dry inert gases these species can be considered to be the most likely evaporation species from a dilute solution of LBE. Thermodynamic evaluation of the system using Gibb's energy minimization indicates that indeed at $700{ }^{\circ} \mathrm{C} \mathrm{BiI}$ is the dominating gas phase molecule over an LBE melt containing mole (b)

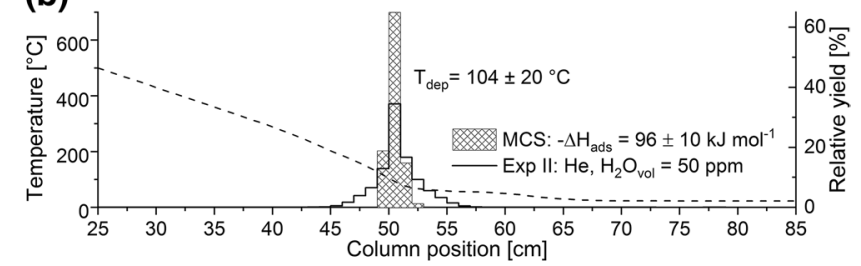

(d)

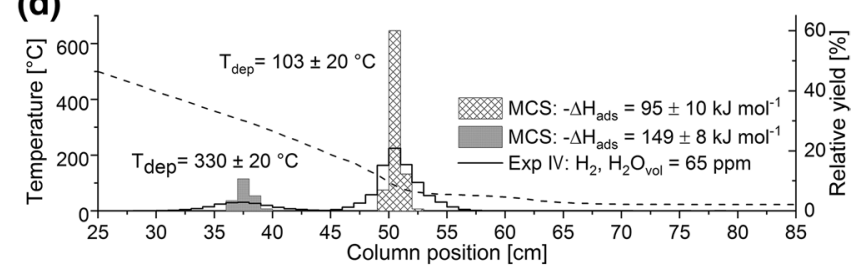

(f)

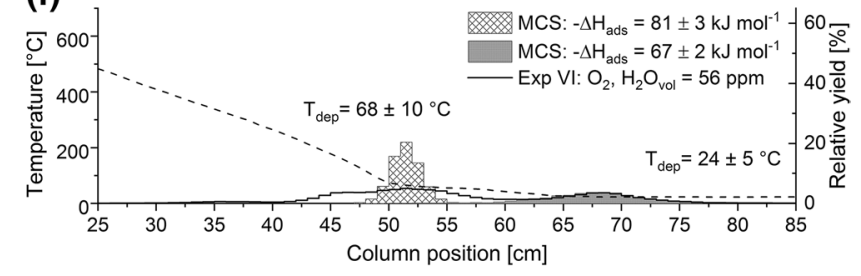

the column and the hatched histograms show the results of the Monte Carlo simulation performed with the given adsorption enthalpy $\Delta H_{\text {ads }}$. The deposition temperature $T_{\text {dep }}$ is given as well

fractions of 0.02 and $10^{-10}$ of tellurium and iodine, respectively. The results of these calculations for iodine containing gaseous species in various gases above an LBE surface at $700{ }^{\circ} \mathrm{C}$ are compiled in Table 2.

From these results, we can see BiI is the dominating gas phase species in dry and moist inert atmosphere. Based on this we assign depositions observed around an adsorption enthalpy of about $-105 \pm 10 \mathrm{~kJ} \mathrm{~mol}^{-1}$ to the bismuth monoiodide, BiI. In dry hydrogen, there are more possibilities with regard to speciation as hydrogen may attack the metal iodides, potentially decomposing them. If this decomposition were to occur, it would lead to formation of hydrogen iodide as the thermodynamic calculations suggest. Hydrogen iodide is a gas at room temperature and ambient pressure [21]. Thus, it should be volatile enough to be carried to the charcoal trap in the present experiments. However, only a few $\mathrm{Bq}$ of iodine were detected in the trap, indicating that $\mathrm{HI}$ is not transported in significant amounts. There is also the alternative possibility of dissociative adsorption occurring, with the breaking of the H-I bond and adsorption of the resulting monatomic I on the surface [22]. According to literature studies [23, 24] monatomic iodine should adsorb to fused silica surfaces at lower deposition temperatures and smaller absolute adsorption enthalpies compared to the depositions we observe in hydrogen. Finally, in experiments on the evaporation of iodine from dilute solutions of LBE in various gas atmospheres performed with the purpose of determining thermodynamic activity data no change in 
Table 2 Equilibrium speciation of gas phase iodine at $700{ }^{\circ} \mathrm{C}$ in the presence of LBE with 2 molar\% tellurium in various atmospheres calculated using Gibbs energy minimization with the GEM equilibrium composition calculation module of HSC 9 [18]

\begin{tabular}{lll}
\hline Gas composition & $\begin{array}{l}\text { Dominating chemical species at } \\
\text { equilibrium }\end{array}$ & Abundance (minor species in brackets) \\
\hline Dry He & BiI & $\sim 61 \%(\sim 34 \% \mathrm{PbI}, \sim 5 \% \mathrm{I})$ \\
Moist He & $\mathrm{BiI}$ & $\sim 61 \%(\sim 34 \% \mathrm{PbI}, \sim 4 \% \mathrm{I}, \sim 1 \% \mathrm{HI})$ \\
Dry $\mathrm{H}_{2}$ & $\mathrm{HI}$ & $\sim 85 \%(\sim 9 \% \mathrm{BiI}, 5 \% \mathrm{PbI}, 1 \% \mathrm{I})$ \\
$\mathrm{Moist}_{2}$ & $\mathrm{HI}$ & $\sim 85 \%(\sim 9 \% \mathrm{BiI}, 5 \% \mathrm{PbI}, 1 \% \mathrm{I})$ \\
Dry $\mathrm{O}_{2}$ & $\mathrm{I}$ & $\sim 100 \%$ \\
$\mathrm{Moist}_{2}$ & $\mathrm{I}$ & $\sim 100 \%$ \\
\hline
\end{tabular}

Listed are the dominating chemical species in the gas phase at equilibrium with their total abundance. The abundance of secondary species occurring in non-negligible amounts is given in brackets volatility has been observed when going from helium to hydrogen carrier gas [25], indicating that the chemical process underlying the evaporation in both gases is similar. The formation of $\mathrm{HI}$ in a gaseous mixture of hydrogen and iodine has been extensively discussed in literature [21, 26, 27]. The mechanisms discussed include either bimolecular elementary processes involving $I_{2}$ molecules or termolecular processes involving collisions of two iodine atoms with a hydrogen molecule. Both these reaction pathways are extremely unlikely to occur in a system with only carrier free amounts of iodine present. From these considerations along with the observed adsorption enthalpy of $-105 \pm 10 \mathrm{~kJ} \mathrm{~mol}^{-1}$ we conclude the iodine species transported and deposited in hydrogen gas is likely BiI and not monatomic iodine from decomposition of HI.

In one hydrogen experiment a minor higher temperature deposition was observed at $330{ }^{\circ} \mathrm{C}$ yielding an adsorption enthalpy of $-149 \pm 8 \mathrm{~kJ} \mathrm{~mol}^{-1}$. The source of this deposition is not entirely clear. However, one explanation might be the formation of cesium iodide from a contamination present in this one single experiment, where the sample boat used as sample holder was contaminated with a tiny amount of cesium from a different experiment. During experiments in inert or oxidizing atmospheres such a cesium contamination would remain in the boat as $\mathrm{CsO}_{2}$ or $\mathrm{CsOH}$ and not interfere with the experiment. However, upon heating in hydrogen it is possible that these compounds would decompose to allow metallic cesium to react with iodine emerging form the LBE to form CsI. The deposition of carrier free amounts of cesium chloride to fused silica occurs around $350{ }^{\circ} \mathrm{C}$, bolstering the CsI assignment of this deposition [28]. While this is not the desired result for this particular experiment, the adsorption chemistry for radionuclide pairs such as Cs and $I$ is considered an important subject in this field.

In oxygen gas the metal iodides can react with oxygen forming free mono-atomic iodine as well as iodine oxides, or possibly hydroxides with traces of moisture. At the same time, metal oxides and/or hydroxides of lead and bismuth are formed. The assumption that the iodine in metal iodides will be oxidized in oxygen while at the same time metal oxides are formed is supported by the relatively low stability of metal iodides and the comparatively high stability of the heavy metal oxides formed. Two reactions can be considered as the most prominent in the system of metal iodides and oxygen: the first being the oxidation of BiI to a bismuth oxide and monatomic iodine, which is then partially followed by the further oxidation of the iodine to form iodine oxides or hydroxides, with the $\mathrm{OH}$-groups originating from surface silanol groups. These silanol groups are $\mathrm{OH}-$ groups attached to the silica surface resulting from adsorption of ambient moisture, which are retained on the surface unless the surface is treated with very high temperatures $\left(>1000{ }^{\circ} \mathrm{C}\right)$ [29]. From these fundamental chemical considerations one can conclude that plausible candidates for the two depositions observed in dry oxygen carrier gas are monoatomic iodine and iodine oxides and/or hydroxides.

Using the adsorption enthalpies observed in the chromatograms where oxygen is the carrier gas in empirical correlations developed for elements on fused silica relating their adsorption enthalpies to their sublimation enthalpies (Fig. 3) we can see a good fit when we assign the peak with deposition temperatures around $68{ }^{\circ} \mathrm{C}$ and adsorption enthalpies from -75 to $-85 \mathrm{~kJ} \mathrm{~mol}^{-1}$ to monatomic iodine. For

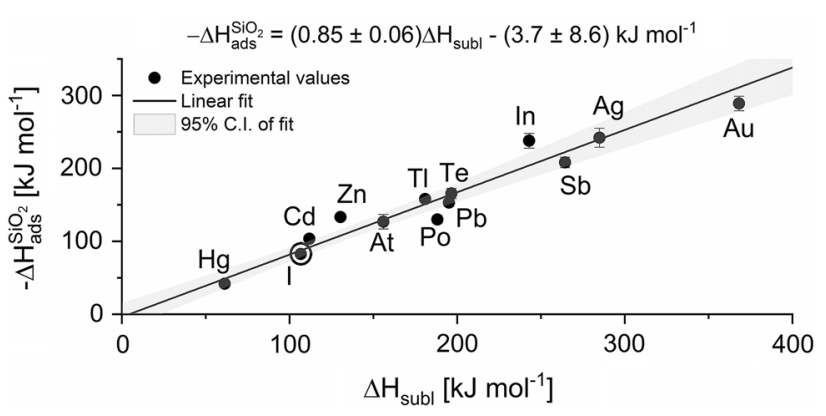

Fig. 3 Experimentally determined correlation between the two state functions of adsorption enthalpy and sublimation enthalpy for elements adsorbing to a fused silica surface, iodine highlighted with a circle. Above the figure, the equation for the fit is displayed along with $95 \%$ confidence interval ranges. Figure adapted with permission from [14] with value for $\mathrm{Tl}$ added 

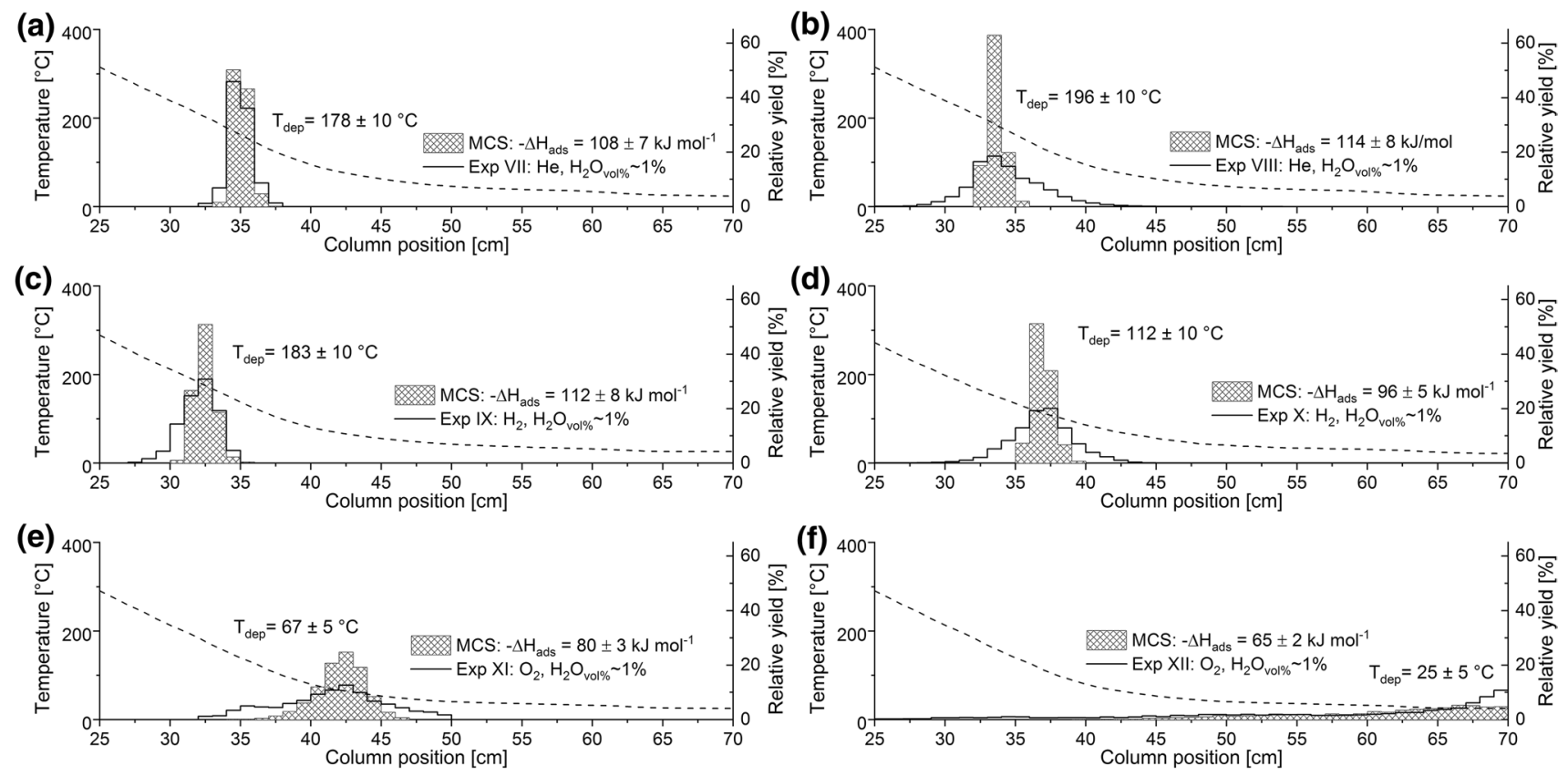

Fig. 4 Histograms of the iodine deposition patterns (black solid lines) observed in the experiments with fused silica columns in water saturated carrier gases. The dashed black line represents the temperature

gradient over the column and the hatched histograms show the results of the Monte Carlo simulation performed with the given adsorption enthalpy $\Delta H_{\text {ads }}$. The deposition temperature $T_{\text {dep }}$ is given as well

experiment VI in Fig. 2f, there is a shoulder present on the peak in a position corresponding to an adsorption enthalpy of $-104 \mathrm{~kJ} \mathrm{~mol}^{-1}$, suggesting a deposition of BiI which has experienced partial decomposition into monatomic iodine.

With $\Delta H_{\text {subl }}(I)=106.76 \mathrm{~kJ} \mathrm{~mol}^{-1}$ [30] the fit yields an expected adsorption enthalpy of atomic iodine as $-\Delta H_{\mathrm{ads}}(I)=87 \pm 15 \mathrm{~kJ} \mathrm{~mol}^{-1}$.

The observed adsorption enthalpies are also consistent with two previously determined values of $-92 \mathrm{~kJ} \mathrm{~mol}^{-1}$ and $-72 \mathrm{~kJ} \mathrm{~mol}^{-1}$ for monatomic iodine on fused silica [23, 24]. Similarly, an increased volatility is observed when changing the carrier gas from inert $\left(\mathrm{N}_{2}\right)$ to an $\mathrm{N}_{2} / \mathrm{O}_{2}$ mix, which indicates formation of oxygen containing volatile iodine species [31]. Even though there exists a similar correlation relating the sublimation and adsorption enthalpies for oxides on fused silica, this method cannot be used here to identify species because the postulated chemical species do not exist in the solid phase and thus no sublimation enthalpy data exists.

The results of experiments in moist helium and hydrogen are similar to those observed for dried helium and hydrogen carrier gases. After a careful statistical analysis (see supplementary information available online), we attribute the depositions in dry and moist helium and hydrogen to one single species. This seems reasonable also from an experimental point of view. Neither systematic deposition changes nor multiple peaks occurring in one single experiment were observed while varying the chemical conditions, yielding no hints to a potential formation of more than one

species. However, the analysis also reveals that two species with adsorption enthalpies as close as $20 \mathrm{~kJ} / \mathrm{mol}$ cannot be distinguished in the steeper part of the temperature gradient. This indicates that the deposited species-tentatively identified as BiI for the dried gases-is not sensitive to water impurities and thus prevails in the moist carrier gases. The observed variations in adsorption enthalpies may result from the influence of the moist carrier gas on the surface silanol coverage rather than on chemical speciation changes of the iodine [17]. For the experiments in oxygen carrier gas potential products of a reaction of the assigned iodine containing species with $\mathrm{H}_{2} \mathrm{O}$ would be for example the family of iodic/ iodous acids, limited of course to those containing only one iodine atom per molecule due to the carrier free iodine presence. Indeed, some variations compared to the dry case are observed when using moist oxygen as a carrier gas. In one of the experiments only a single peak is detected at a position that is consistent with the deposition assigned to monatomic iodine in the dry experiments. Similarly to one experiment in the dry conditions, there is formation of a peak shoulder in Fig. 4e), corresponding to an adsorption enthalpy of $-98 \mathrm{~kJ} \mathrm{~mol}^{-1}$ indicating again an only partial oxidation of BiI. In the second experiment, the activity is very smeared out. The activity corresponding to the now missing peak that was observed in the first experiment was instead found in the charcoal filter. The inconsistency between the two experiments may be due to variations in the moisture contents in the carrier gas leading to different species or as of 
yet unknown effects possibly resulting from surface variations by moisture. Furthermore, the temperature gradient applied in the present series of experiments is very flat in the room temperature region, which is not advantageous for the study of such very volatile species, since slight changes of the temperature or gas flow might significantly shift the deposition laterally. Overall, the results obtained here indicate that moisture does have a considerable influence on the speciation of iodine evaporated from LBE in oxygen gas, but the details underlying these effects cannot be resolved using the presently available apparatus. For such studies, an experimental setup with a temperature gradient extending significantly below room temperature and a more precise control of moisture content should be developed. The current two setups are capable of determining adsorption enthalpies down to $-\Delta \mathrm{H}_{\mathrm{ads}}=65 \mathrm{~kJ} \mathrm{~mol}^{-1}$ for both setups, which corresponds roughly to an adsorption temperature of $25^{\circ} \mathrm{C}$.

\section{Conclusions}

When evaporated from LBE in dry and moist helium or hydrogen carrier gas, iodine deposits on a fused silica surface with an adsorption enthalpy of approximately $-104 \pm 10 \mathrm{~kJ} \mathrm{~mol}^{-1}$. Statistical evaluations showed that the depositions with individual adsorption enthalpy values ranging from -95 to $-114 \mathrm{~kJ} \mathrm{~mol}^{-1}$ can be assigned to one single species, tentatively identified as bismuth monoiodide, BiI. This assignment is supported by results from thermodynamic calculations showing that this molecule is the dominating gas phase species over a melt of LBE containing tellurium and iodine at concentration levels and temperatures similar to the experimental conditions. It is noteworthy that in hydrogen carrier gas no indications of decomposition into more volatile species such as monoatomic iodine or hydrogen iodide were observed. Also, the addition of moisture to helium and hydrogen carrier gases has no significant influence on the depositions. One spurious peak in one single experiment at $\sim 330{ }^{\circ} \mathrm{C}$ is tentatively assigned to $\mathrm{CsI}$, with the cesium coming from a minute contamination of the sample boat. In all experiments in oxidizing conditions with dry and moist oxygen as a carrier gas, species with higher volatility compared to BiI are formed with adsorption enthalpies ranging from approximately $-85 \mathrm{~kJ} \mathrm{~mol}^{-1}$ to $-65 \mathrm{~kJ} \mathrm{~mol}^{-1}$. The depositions with an adsorption enthalpy around $-85 \mathrm{~kJ} \mathrm{~mol}^{-1}$ can be assigned to monatomic iodine based on empirical correlation to tabulated sublimation enthalpies. The most likely speciation for the depositions with smaller absolute values of adsorption enthalpies is iodine oxides and/or hydroxides. For some experiments done with oxygen carrier gas an elevated amount of iodine was present in the charcoal trap indicating that more volatile species are present in the system or that a partial transport reaction occurs. Thermal gradients extending to lower temperatures must be utilized to measure the adsorption behavior of these species. While oxygen increases the volatility of the evaporated iodine, it simultaneously introduces a retention effect in the LBE, preventing full evaporation. This effect is likely caused by the formation of an oxide layer which impedes the iodine release.

Author contributions EK: conceptualization, methodology, software, validation, formal analysis, investigation, writing-original draft, visualization, JN: conceptualization, validation, data curation, writing—review \& editing, visualization, supervision, project administration, funding acquisition, RE: validation, methodology, software, writing-review \& editing, visualization, AA: validation, data curation, writing-review \& editing, IID: methodology, resources, av: methodology, resources, AT: validation, writing-review \& editing, supervision.

Funding Open Access funding provided by Lib4RI - Library for the Research Institutes within the ETH Domain: Eawag, Empa, PSI \& WSL. This work was funded by the project MYRTE under EURATOM HORIZON2020 Grant Agreement No. 662186.

\section{Compliance with ethical standards}

Conflict of interest The authors declare that they have no conflict of interest.

Open Access This article is licensed under a Creative Commons Attribution 4.0 International License, which permits use, sharing, adaptation, distribution and reproduction in any medium or format, as long as you give appropriate credit to the original author(s) and the source, provide a link to the Creative Commons licence, and indicate if changes were made. The images or other third party material in this article are included in the article's Creative Commons licence, unless indicated otherwise in a credit line to the material. If material is not included in the article's Creative Commons licence and your intended use is not permitted by statutory regulation or exceeds the permitted use, you will need to obtain permission directly from the copyright holder. To view a copy of this licence, visit http://creativecommons.org/licenses/by/4.0/.

\section{References}

1. Ait Abderrahim H, Baeten P, De Bruyn D, Heyse J, Schuurmans P, Wagemans J (2010) MYRRHA, a multipurpose hYbrid research reactor for high-end applications. Nucl Phys News. https://doi. org/10.1080/10506890903178913

2. Cohen BL (1983) Breeder reactors: a renewable energy source. Am J Phys. https://doi.org/10.1119/1.13440

3. Nuclide Datasheets, Nucleonica GmbH (2019) Nucleonica Nuclear Science Portal, www.nucleonica.com, Version 3.0.151.0001, Karlsruhe, Germany

4. EURATOM (2017) Contribution to the Generation IV International Forum Systems in the period 2005-2014 and future outlook, EUR 28391 EN. Publications Office of the European Union, Luxembourg

5. Polmar N, Moore KJ (2004) Cold war submarines: the design and construction of U.S. and Soviet Submarines, 1945-2001. Potomac Books Inc, Virginia, USA 
6. Gonzalez-Prieto B, Marino A, Lim J, Rosseel K, Martens JA, Rizzi M, Neuhausen J, Van den Bosch J, Aerts A (2014) Use of the transpiration method to study polonium evaporation from liquid lead-bismuth eutectic at high temperature. Radiochim Acta. https://doi.org/10.1515/ract-2014-2263

7. Gonzalez-Prieto B, Lim J, Rosseel K, Martens JA, Aerts (2016) Polonium evaporation from liquid lead-bismuth eutectic with different oxygen content. J Radioanal Nucl Chem. https://doi. org/10.1007/s10967-015-4670-8

8. Hammer-Rotzler B, Neuhausen J, Boutellier V, Wohlmuther M, Zanini L, David JC, Türler A, Schumann D (2016) Distribution and surface enrichment of radionuclides in lead-bismuth eutectic from spallation targets. Eur Phys J Plus. https://doi.org/10.1140/ epjp/i2016-16233-1

9. Hammer-Rotzler B, Neuhausen J, Vockenhuber C, Boutellier V, Wohlmuther M, Türler A, Schumann D (2015) Radiochemical determination of ${ }^{129} \mathrm{I}$ and ${ }^{36} \mathrm{Cl}$ in MEGAPIE, a proton irradiated lead-bismuth eutectic spallation target. Radiochim Acta. https:// doi.org/10.1515/ract-2015-2420

10. Dai Y Final Report on MEGAPIE Target Irradiation and PostIrradiation Examination, https://www.osti.gov/biblio/1188406/ Accessed 5 Jun 2020

11. Steinhauser G (2014) Fukushima's forgotten radionuclides: a review of the understudied radioactive emissions. Environ Sci Technol. https://doi.org/10.1021/es405654c

12. Campbell DO, Malinauskas AP, Stratton WR (1981) The chemical behavior of fission product iodine in light water reactor accidents. Nucl Technol. https://doi.org/10.13182/NT81-A32615

13. Maugeri EA, Neuhausen J, Eichler R, Piguet D, Melo Mendonça T, Stora T, Schumann D (2014) Thermochromatography study of volatile polonium species in various gas atmospheres. J Nucl Mater. https://doi.org/10.1016/j.jnucmat.2013.11.024

14. Steinegger P, Asai M, Dressler R, Eichler R, Kaneya Y, Mitsukai A, Nagame Y, Piguet D, Sato TK, Schädel M, Takeda S, Toyoshima A, Tsukada K, Türler A, Vascon A (2016) Vacuum chromatography of $\mathrm{Tl}$ on $\mathrm{SiO}_{2}$ at the single-atom level. J Phys Chem C. https://doi.org/10.1021/acs.jpcc.5b12033

15. Eichler R, Eichler B, Gäggeler HW, Jost DT, Dressler R, Türler A (1999) The gas phase oxide and oxyhydroxide chemistry of trace amounts of rhenium. Radiochim Acta. https://doi.org/10.1524/ ract.1999.87.34.151

16. Silva CM, Rosseel M, Kirkegaard MC (2018) Radiation-induced changes in quartz, a mineral analog of nuclear power plant concrete aggregates. Inorg Chem. https://doi.org/10.1021/acs.inorg chem.8b00096

17. Zvara I (2008) The inorganic chemistry of heavy elements, 1st edn. Springer, Dordrecht
18. Roine A (2018) HSC Chemistry ${ }^{\circledR}$ [Software], Outotec, Pori, Finland. Software available at www.outotec.com/HSC

19. Karlsson E, Neuhausen J, Eichler R, Vögele A, Türler A (2020) Adsorption properties of iodine on fused silica surfaces when evaporated from tellurium in various atmospheres. J Radioanal Nucl Chem. https://doi.org/10.1007/s10967-020-07326-y

20. Binnewies M, Milke E (2002) Thermochemical data of elements and compounds, 2nd edn. Wiley-VCH, Weinheim

21. Wiberg N, Holleman AF (2007) Lehrbuch der Anorganischen Chemie, 102nd edn. De Gruyter, Berlin

22. Eichler B, Baltensperger U, Kalberer M (1998) PSI annual report 1998/Annex IIIA. Paul Scherrer Institut, Villigen

23. Eichler B, Domanov VP (1975) Verflüchtigung von Radionukliden im Luftstrom und Ihre Abscheidung im Temperaturgradientrohr. J Radioanal Chem. https://doi.org/10.1007/BF02516873

24. Eichler B (1997) Das Verhalten flüchtiger Radionuklide im Temperaturgradientrohr unter Vakuum. Report ZfK-346, Rossendorf, Germany

25. Danilov II, Vögele A, Hermann D, Eichler R, Türler A, Neuhausen J (2018), Review of experiments on iodine evaporation from liquid lead-bismuth eutecticum, part II: preliminary results. Annual Report 2018, Laboratory of Radiochemistry, Paul Scherrer Institut, Villigen, Switzerland, p 46

26. Sullivan JH (1967) Mechanism of the "Bimolecular" hydrogeniodine reaction. J Chem Phys DOI 10(1063/1):1840433

27. Raff LM, Thompson DJ, Sims LB, Porter RN (1972) Dynamics of the molecular and atomic mechanisms for the hydrogen-iodine exchange. J Chem Phys DOI 10(1063/1):1677149

28. Merinis J, Bouissieres G (1969) Étude de la migration de radioéléments dans un tube à gradient de température. Radiochim Acta. https://doi.org/10.1524/ract.1969.12.3.140

29. Zhuravlev LT (1987) Concentration of hydroxyl groups on the surface of amorphous silicas. Langmuir. https://doi.org/10.1021/ la00075a004

30. Barin I (1995) Thermochemical data of pure substances, 3rd edn. Wiley-VCH, Weinheim

31. Bächmann K, Matschoss V (1975) Separation of nuclear reaction products in the gas phase-I: separation of Tc in a flow of oxygen. J Inorg Nucl Chem. https://doi.org/10.1016/0022-1902(75)80116 $-3$

Publisher's Note Springer Nature remains neutral with regard to jurisdictional claims in published maps and institutional affiliations. 